\title{
Deposição de gotas no dossel e controle químico de Phakopsora pachyrhizi na soja
}

\author{
Nédio R. Tormen ${ }^{1}$, Felipe D. L. da Silva ${ }^{1}$, Mônica P. Debortoli ${ }^{1}$, \\ Juliano D. Uebel1', Diego D. Fávera ${ }^{1}$ \& Ricardo S. Balardin'1
}

\begin{abstract}
RESUMO
A deposição de gotas no dossel da cultura da soja com três pontas de pulverização e programas de controle químico da ferrugem asiática foram avaliados em experimento conduzido em campo, no município de Itaara, RS. Os tratamentos foram arranjados no delineamento de blocos ao acaso com quatro repetições, em esquema fatorial $2 \times 3 \times 3$, representados por duas cultivares de soja, três pontas de pulverização e três programas de controle da ferrugem asiática. Os fungicidas foram aplicados nos estádios R1 e R4 da cultura. As variáveis analisadas foram: densidade de gotas, diâmetro mediano volumétrico (DMV), índice de área foliar (IAF), severidade da ferrugem asiática e rendimento de grãos da cultura. Elaborou-se, com base nos dados de severidade da ferrugem asiática, a área abaixo da curva de progresso da ferrugem (AACPF). As pontas de pulverização estudadas diferiram significativamente quanto à deposição de gotas nos três terços do dossel vegetal, DMV, AACPF e rendimento de grãos. O incremento médio no rendimento de grãos pela aplicação de fungicidas foi de 53,17\% na cultivar Asgrow 8000 RG e 29,89\% na cultivar Agiara RR. O IAF das cultivares influenciou na penetração e deposição de gotas no dossel da cultura.
\end{abstract}

Palavras-chave: Glycine max, ferrugem asiática, pontas de pulverização

\section{Drop deposition on canopy and chemical control of Phakopsora pachyrhizi in soybeans}

\begin{abstract}
Drop deposition on soybean canopy with three spray nozzles and chemical control programs of asian soybean rust were evaluated in two soybean cultivars, in a study carried out in Itaara, RS. The treatments were arranged under completely randomized block design with four replications, in a factorial design $2 \times 3 \times 3$, utilizing two soybean cultivars, three spray nozzles and three chemical control programs. The fungicide applications were accomplished in R1 and R4 growth stages. Drop density, volumetric medium diameter (VMD), leaf area index (LAI), disease severity and grain yield were the variables measured. Based on the severity data of asian rust the area under disease progress curve (AUDPC) was calculated. The spray nozzles studied were significantly different in relation to drop deposition on soybean canopy, VMD, AUDPC and grain yield. The soybean grain yield was increased by $53.17 \%$ on Asgrow 8000 RG and $29.89 \%$ on Agiara RR cultivar, as a result of fungicide application. The LAI of cultivars influenced drop deposition and penetration into canopy.
\end{abstract}

Key words: Glycine max, asian rust, spray nozzles 


\section{INTRODUÇÃO}

Nas últimas safras a ferrugem asiática (Phakopsora pachyrhizi Syd. \& P. Syd.) tem sido o principal problema de ordem fitossanitária da cultura da soja em virtude da desfolha prematura, que causa perdas significativas na produção (Hartman et al., 2005). A desfolha precoce impede a completa formação e o enchimento dos legumes diminuindo, em consequência, o número e o peso final dos grãos (Soares et al., 2004; Medice et al., 2007).

A utilização de variedades precoces, a redução do período destinado à semeadura e a utilização de cultivares com algum nível de resistência, são estratégias significativas no manejo da doença. Para Juliatti et al. (2005), o manejo correto deste mal passa pelas estratégias de: redução da dispersão de inóculo, uso da resistência parcial, fungicidas de maior eficácia e tecnologia de aplicação adequada aos sistemas de produção. Mesmo com a utilização de todas essas estratégias, Santos et al. (2007) afirmam que a ferrugem asiática tem seu controle baseado sobretudo no uso de fungicidas.

O sucesso do controle químico da ferrugem asiática depende da tecnologia de aplicação empregada. Nas aplicações realizadas atualmente a quantidade de princípio ativo que, na verdade, atinge o alvo, é muito menor do que a aplicada (Chaim et al., 1999). Neste sentido, o transporte do ingrediente ativo para o interior do dossel é condição básica para o controle eficaz de pragas e doenças e, à medida em que o ciclo da cultura avança, atingir as camadas inferiores do dossel se torna um desafio cada vez maior. Desta forma, a penetração de gotas no dossel da cultura é aspecto fundamental sobremaneira para doenças que iniciam a patogênese nas folhas baixeiras, como é o caso de Phakopsora pachyrhizi (Raetano, 2007).

A qualidade da cobertura e a redução das perdas por deriva e evaporação também influenciam diretamente na eficácia biológica dos fungicidas (Ozeki \& Kunz, 1998). A seleção das pontas de pulverização é uma das maneiras de se obter maior cobertura e deposição do ingrediente ativo sobre o alvo biológico. Segundo Christofoletti (1999), necessita-se, para uma boa eficácia no controle de doenças, de cobertura de 30 a 40 gotas $\mathrm{cm}^{-2}$ para fungicidas sistêmicos e entre 50 e 70 gotas $\mathrm{cm}^{-2}$ para fungicidas protetores. Trabalhando com volumes de calda de 120 e $160 \mathrm{~L} \mathrm{ha}^{-1}$, Ugalde (2005) observou uma cobertura de gotas mínima eficiente para fungicidas sistêmicos e protetores de 45 e 60 gotas $\mathrm{cm}^{-2}$, respectivamente.

Com um mesmo volume de calda a quantidade de gotas produzidas na pulverização é inversamente proporcional ao seu diâmetro, definido pela ponta de pulverização e pressão de trabalho utilizada. Esses dois fatores afetam a cobertura do dossel vegetal com fungicida e o potencial de deriva da gota. Assim, as pontas de pulverização não só são componentes fundamentais em um pulverizador mas estão estreitamente relacionadas com a vazão, tamanho e distribuição das gotas produzidas, pressão de trabalho e velocidade de aplicação. Além disso, a escolha da ponta de pulverização permite adequarse o tamanho das gotas produzidas às condições de aplicação garantindo, ao mesmo tempo, eficácia biológica e segurança ambiental (Cunha et al., 2003).
Gotas grandes são menos suscetíveis à deriva; entretanto, podem comprometer a cobertura do alvo. Por outro lado, gotas pequenas são facilmente transportadas pelo vento, embora propiciem maior cobertura do alvo, condição esta desejada especialmente quando se trata de fungicidas protetores (Cunha et al., 2006). Walklate (1992) e Cross et al. (2001) afirmam que gotas de pequeno diâmetro são extremamente eficazes no controle de doenças.

Além das características inerentes ao espectro das gotas produzidas o sucesso de uma ponta de pulverização em atingir as camadas inferiores do dossel vegetal depende também das características de arquitetura da cultivar em questão. Cultivares que possuem maior IAF e mais ramificações laterais possibilitam mais rapidamente o fechamento das entrelinhas dificultando, assim, a passagem das gotas para as camadas inferiores do dossel. Em estudos sobre a deposição de gotas no dossel vegetativo, Ozkan et al. (2006) demonstraram que com um IAF de 6,4 a maioria das gotas produzidas ficou retida nas folhas do topo do dossel, condição que favorece a proliferação da doença nas folhas baixeiras que, além de estarem quimicamente desprotegidas, possuem um microclima mais propício ao desenvolvimento da doença.

Diversos trabalhos na literatura têm avaliado a eficiência de diferentes pontas de pulverização, pressão de trabalho e volume de calda para o controle de Phakopsora pachyrhizi (Cunha et al., 2006; 2008; Viana et al., 2008), porém ainda são escassos trabalhos que considerem a variação na arquitetura das plantas existente entre cultivares. A necessidade de se atentar para a eficiência diferenciada de pontas de pulverização em colocar o fungicida nas camadas inferiores do dossel vegetal, considerando as variações de arquitetura entre cultivares, motivou a realização deste estudo, cujo objetivo foi avaliar a deposição de gotas e a eficácia de programas de controle químico da ferrugem asiática aplicados com diferentes pontas de pulverização e em cultivares com diversas características de arquitetura.

\section{Material E MÉTODOS}

O experimento foi conduzido em campo, no município de Itaara, região central do Rio Grande do Sul, durante a safra agrícola 2007/2008. Utilizou-se o sistema de semeadura direta em sucessão à cultura do trigo, com espaçamento entre linhas de $0,45 \mathrm{~m}$ e densidade de 270.000 plantas $\mathrm{ha}^{-1}$. As unidades experimentais possuíam cinco metros de comprimento e cinco linhas de largura, totalizando $11,25 \mathrm{~m}^{2}$. Com vista à mensuração das variáveis estudadas, desconsideraram-se as duas linhas externas e $0,5 \mathrm{~m}$ de cada extremidade, resultando em área útil total de $5,4 \mathrm{~m}^{2}$ por unidade experimental.

Os tratamentos foram dispostos no delineamento de blocos ao acaso em esquema fatorial $2 \times 3 \times 3$. Os fatores estudados foram duas cultivares de soja (Asgrow $8000 \mathrm{RG}$ e Agiara RR), três pontas de pulverização (Turbo Teejet ${ }^{\circledR}$ TT 11002 de jato plano de ângulo grande, Teejet XR 11002 de jato plano de faixa ampliada e Twinjet TJ-60 11002 de jato plano duplo) e três programas de controle químico (testemunha sem controle, Azoxistrobina + Ciproconazol $\left(60+24 \mathrm{~g} \mathrm{ha}^{-1}\right.$ de i.a. $) \mathrm{e}$ 
Tebuconazol + Carbendazim $\left(100+250 \mathrm{~g} \mathrm{ha}^{-1}\right.$ de i.a. $\left.)\right)$. As aplicações foram realizadas nos estádios fenológicos R1 e R4 da cultura, segundo escala de Fehr \& Caviness (1981), com auxílio de pulverizador costal pressurizado a $\mathrm{CO}_{2}$, provido de barra de aplicação com quatro pontas de pulverização. A pressão de trabalho e o volume de calda foram iguais para as três pontas sendo, respectivamente, de $270 \mathrm{kPa}$ e $150 \mathrm{~L} \mathrm{ha}^{-1}$. A pressão de trabalho utilizada estava dentro das recomendações do fabricante e possibilitou a produção de gotas de diferentes tamanhos, objetivo já buscado com a utilização de diferentes pontas de pulverização.

A deposição de gotas foi medida através de cartões hidrossensíveis dispostos nos terços inferior, mediano e superior do dossel das plantas de soja. Os cartões foram fixados com o auxílio de suporte metálico com regulagem da altura dos cartões, adequando-se à altura em relação ao solo, conforme a estatura de cada cultivar mantendo-se, assim, o padrão de coleta por terço. Após a aplicação os cartões foram identificados e acondicionados em sacos plásticos e posteriormente escaneados em scanner HP 300 com resolução de 1200 dpi. A análise das imagens foi realizada no software $\mathrm{CIR}^{\circledR}$, possibilitando a obtenção dos valores de diâmetro mediano volumétrico (DMV) em $\mu \mathrm{m}$ e densidade de gotas $\left(\right.$ gotas $\mathrm{cm}^{-2}$ ). Para a análise estatística desses parâmetros considerou-se o valor médio obtido para os três programas de controle químico utilizados, uma vez que não houve diferença significativa entre os mesmos. Desta forma, a análise de variância para esses dois parâmetros foi realizada como um fatorial $2 \times 3$, representado por duas cultivares de soja e três pontas de pulverização.

No momento das aplicações também foi estimado o índice de área foliar das cultivares utilizando-se da metodologia dos discos (Peixoto, 1998). Para tal, foram coletadas, aleatoriamente, três plantas em cada uma das parcelas experimentais, das quais foram retiradas todas as folhas. Com o auxílio de um perfurador metálico foram retirados discos foliares de área conhecida em quatro posições do limbo foliar, em cada folíolo, evitando-se a amostragem da nervura central; em seguida, os discos foliares de área conhecida foram colocados em estufa com circulação de ar a $70^{\circ} \mathrm{C}$ durante $36 \mathrm{~h}$, visando à obtenção da matéria seca. Utilizou-se o mesmo procedimento para a secagem das folhas das quais foram retirados os discos foliares. Obteve-se o IAF pela relação entre a matéria seca dos discos foliares e a matéria seca total (folhas + discos foliares).

Obteve-se a severidade da doença atribuindo-se notas da porcentagem de área foliar com sintomas típicos da doença, às metades superior e inferior do dossel vegetal em dez plantas por unidade experimental, utilizando-se escala diagramática proposta por Godoy et al. (2006), em avaliações semanais realizadas a partir dos primeiros sintomas da doença. A leitura da severidade da doença possibilitou a elaboração da área abaixo da curva de progresso da ferrugem (AACPF), calculada a partir de uma média ponderada da severidade, atribuindo-se peso de $30 \%$ para o terço inferior e $70 \%$ para o terço superior do dossel vegetal. A AACPF foi obtida pela soma das áreas trapezoidais (Campbell \& Madden, 1990).

Obteve-se o rendimento de grãos através do corte e da trilha das plantas na área útil das unidades experimentais. A determinação da umidade foi realizada no momento da colheita e o cálculo do rendimento final em $\mathrm{kg} \mathrm{ha}^{-1}$ foi determinado com base no peso da amostra, após conversão da umidade para $13 \%$.

Os dados obtidos foram submetidos à análise de variância e as médias ao teste de comparação múltipla de médias de Tukey a 5\% de probabilidade de erro, utilizando-se o pacote estatístico Assistat.

\section{RESULTADOS E DISCUSSÃO}

As pontas de pulverização estudadas apresentaram desempenho diferenciado em relação ao tamanho das gotas produzidas e também na sua deposição, nos três terços do dossel das plantas de soja. Houve diferença significativa na AACPF entre cultivares, pontas de pulverização e programas de controle e para a interação entre os três fatores. A análise de variância dos dados de rendimento de grãos apresentou valores de F significativos para os três fatores estudados, tal como para a interação entre cultivares e pontas de pulverização e também para a interação tripla.

Apesar de não diferir significativamente das demais, em alguns casos a ponta TJ-60 11002 apresentou os menores valores de DMV em ambas as aplicações, independentemente do terço do dossel analisado (Tabela 1). Esta ponta produziu gotas de tamanho médio. O maior DMV foi obtido pela ponta TT 11002, produzindo gotas que variaram de grossa a extremamente grossa nos três terços do dossel avaliados e em ambas as aplicações. Viana et al. (2008) estudando diferentes pontas de pulverização(XR11002, TT11002, TXA-8002 e TJ608002), já haviam relatado a produção de gotas mais grossas por essa ponta, que apresentou o maior DMV em todo o dossel da soja. A ponta XR 11002 produziu gotas que variaram de média a grossa, indicando tamanho de gotas intermediário, entre a TJ-60 11002 e a TT 11002.

Relacionando os resultados supracitados com os obtidos para densidade de gotas (Tabela 2), reforçam-se dados já citados na literatura (Ozeki \& Kunz, 1998) de que gotas com menor diâmetro têm maior capacidade de penetrar no dossel vegetal. Este padrão de deposição de gotas foi observado nas duas cultivares utilizadas; no entanto, a magnitude da diferença entre as pontas estudadas variou conforme a cultivar; tem-se, então, que referida diferença se deve, provavelmente, às condições de arquitetura e fechamento do dossel entre as cultivares. $\mathrm{Na}$ aplicação realizada em R1 a ponta TJ-60 11002 proporcionou maior deposição de gotas nos três terços do dossel na cultivar Agiara RR, não diferindo da ponta XR 11002, quando considerado o terço superior. A mesma tendência de deposição foi observada na cultivar Asgrow 8000 RG; entretanto, foi significativa apenas no terço superior do dossel vegetal (Tabela 2). Na aplicação em R4 o desempenho das pontas foi semelhante ao obtido em R1 porém a diferença entre as pontas foi mais expressiva na cultivar Asgrow 8000 RG. De forma geral, a ponta TT 11002 foi a que proporcionou a menor deposição de gotas nos três terços do dossel da cultura, em ambas as aplicações. A ponta XR 11002 apresentou deposição de gotas intermediária quando comparada com as demais. Referidos resultados estão 
Tabela 1. Diâmetro Mediano Volumétrico (DMV) nos terços superior, mediano e inferior do dossel da cultura da soja, após a aplicação de fungicida com diferentes pontas de pulverização, em duas cultivares de soja

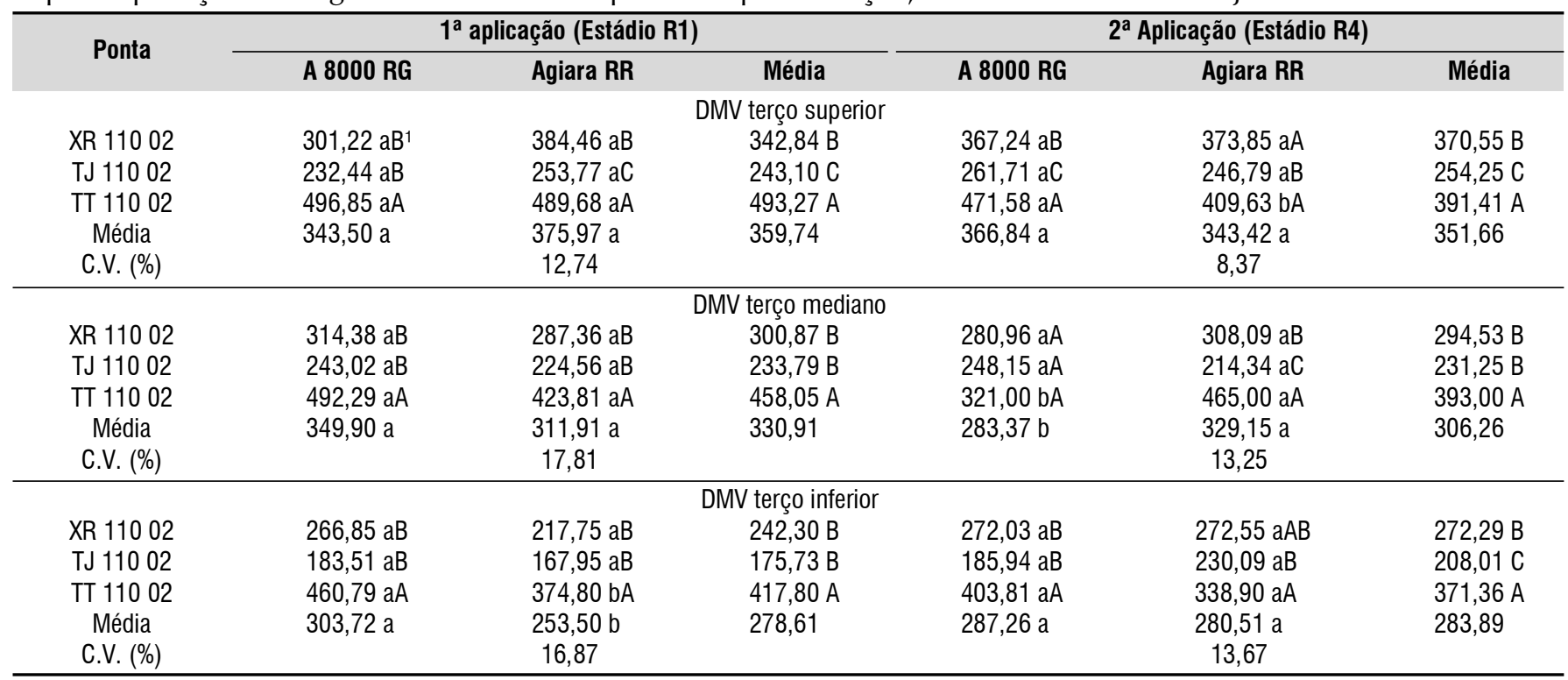

${ }^{1}$ Valores seguidos da mesma letra maiúscula na coluna e minúscula na linha não diferem pelo teste de Tukey a 5\% de probabilidade

Tabela 2. Densidade de gotas (gotas $\mathrm{cm}^{-2}$ ) nos terços superior, mediano e inferior do dossel da cultura da soja, após a aplicação de fungicida com diferentes pontas de pulverização, em duas cultivares de soja

\begin{tabular}{|c|c|c|c|c|c|c|}
\hline \multirow{2}{*}{ Ponta } & \multicolumn{3}{|c|}{$1^{\text {a }}$ aplicação (Estádio R1) } & \multicolumn{3}{|c|}{ 2a Aplicação (Estádio R4) } \\
\hline & A 8000 RG & Agiara RR & Média & A 8000 RG & Agiara RR & Média \\
\hline \multicolumn{7}{|c|}{ Densidade (gotas $\mathrm{cm}^{-2}$ ) - terço superior } \\
\hline XR 11002 & $122,00 \mathrm{bB}$ & 214,67 aA & $168,33 \mathrm{~B}$ & $204,33 \mathrm{aB}$ & $216,67 \mathrm{aAB}$ & $210,50 \mathrm{~B}$ \\
\hline TJ 11002 & 255,67 aA & 252,33 aA & $254,00 \mathrm{~A}$ & $277,00 \mathrm{aA}$ & $262,00 \mathrm{aA}$ & $269,50 \mathrm{~A}$ \\
\hline TT 11002 & $154,33 \mathrm{aB}$ & $156,00 \mathrm{aB}$ & $155,17 \mathrm{~B}$ & $156,67 \mathrm{aB}$ & $186,33 \mathrm{aB}$ & $171,50 \mathrm{C}$ \\
\hline Média & 177,33 B & $207,67 \mathrm{a}$ & 192,50 & $212,67 \mathrm{a}$ & $221,67 \mathrm{a}$ & 217,17 \\
\hline C.V. (\%) & & 12,65 & & & 9,82 & \\
\hline \multicolumn{7}{|c|}{ Densidade (gotas $\mathrm{cm}^{-2}$ ) - terço médio } \\
\hline XR 11002 & $45,00 \mathrm{bA}$ & $95,33 \mathrm{aB}$ & $70,17 \mathrm{~B}$ & $38,00 \mathrm{bA}$ & $95,00 \mathrm{aA}$ & $66,50 \mathrm{~B}$ \\
\hline TJ 11002 & $59,67 \mathrm{bA}$ & $125,00 \mathrm{aA}$ & $92,33 \mathrm{~A}$ & $50,33 \mathrm{bA}$ & $114,33 \mathrm{aA}$ & $82,33 \mathrm{~A}$ \\
\hline TT 11002 & $44,33 \mathrm{bA}$ & $90,00 \mathrm{aB}$ & 67,17 B & $39,67 \mathrm{aA}$ & 16,67 bB & $28,17 \mathrm{C}$ \\
\hline Média & $49,67 \mathrm{~b}$ & $103,44 \mathrm{a}$ & 76,56 & $42,67 \mathrm{~b}$ & $75,33 \mathrm{a}$ & 59,00 \\
\hline C.V. (\%) & & 10,15 & & & 14,70 & \\
\hline \multicolumn{7}{|c|}{ Densidade (gotas $\mathrm{cm}^{-2}$ ) - terço inferior } \\
\hline XR 11002 & $16,33 \mathrm{bA}$ & $49,67 \mathrm{aB}$ & $33,00 \mathrm{~B}$ & $40,67 \mathrm{bB}$ & $84,33 \mathrm{aA}$ & $62,50 \mathrm{~B}$ \\
\hline TJ 11002 & $17,67 \mathrm{bA}$ & $118,33 \mathrm{aA}$ & $68,00 \mathrm{~A}$ & 53,33 bA & $92,67 \mathrm{aA}$ & $73,00 \mathrm{~A}$ \\
\hline TT 11002 & $16,33 \mathrm{bA}$ & $31,00 \mathrm{aC}$ & $23,67 \mathrm{C}$ & $15,33 \mathrm{bC}$ & $25,67 \mathrm{aB}$ & $20,50 \mathrm{C}$ \\
\hline Média & $16,78 \mathrm{~b}$ & $66,33 \mathrm{a}$ & 41,56 & $36,44 \mathrm{~b}$ & $67,56 \mathrm{a}$ & 52,00 \\
\hline C.V. (\%) & & 11,45 & & & 9,41 & \\
\hline
\end{tabular}

de acordo com os obtidos por Ozkan et al. (2006) que, testando diferentes equipamentos de aplicação de fungicidas para o controle da ferrugem asiática, observaram menor deposição de gotas nos terços mediano e inferior do dossel, pelas pontas que produziram gotas grossas. Cunha et al. (2006) também concluíram, avaliando a deposição promovida por diferentes pontas de pulverização na cultura da soja, que a maior cobertura das camadas inferiores do dossel vegetal é obtida quando se empregam pontas que produzem gotas de tamanho menor.

Devido às diferenças nas condições ambientais entre as aplicações em R1 e R4 a simples comparação dos resultados absolutos de densidade de gotas (gotas $\mathrm{cm}^{-2}$ ) se torna inadequada. No entanto, transformando esses valores absolutos para porcentagem de deposição de gotas por terço tem-se uma relação menos dependente das variações ambientais. Na aplicação em R4 percebe-se claramente uma redução considerável na porcentagem de gotas que atingem as camadas medianas e inferiores do dossel vegetal em relação ao total de gotas que atingiu a planta (Figura 1). Tal modificação ocorreu principalmente no terço mediano em que a redução na deposição de gotas pela aplicação em R4 foi de 6,1 e 9,6\%, para as cultivares Asgrow 8000 RG e Agiara RR, respectivamente. Observou-se também, sobretudo na cultivar Agiara RR, aumento de 8,6\% na proporção de gotas retidas no terço superior das plantas de soja. Resultados semelhantes foram encontrados por Farinha et al. (2009) que, estudando a deposição de calda em duas cultivares de soja, observaram depósitos na região apical quase três vezes superior aos da região basal. 


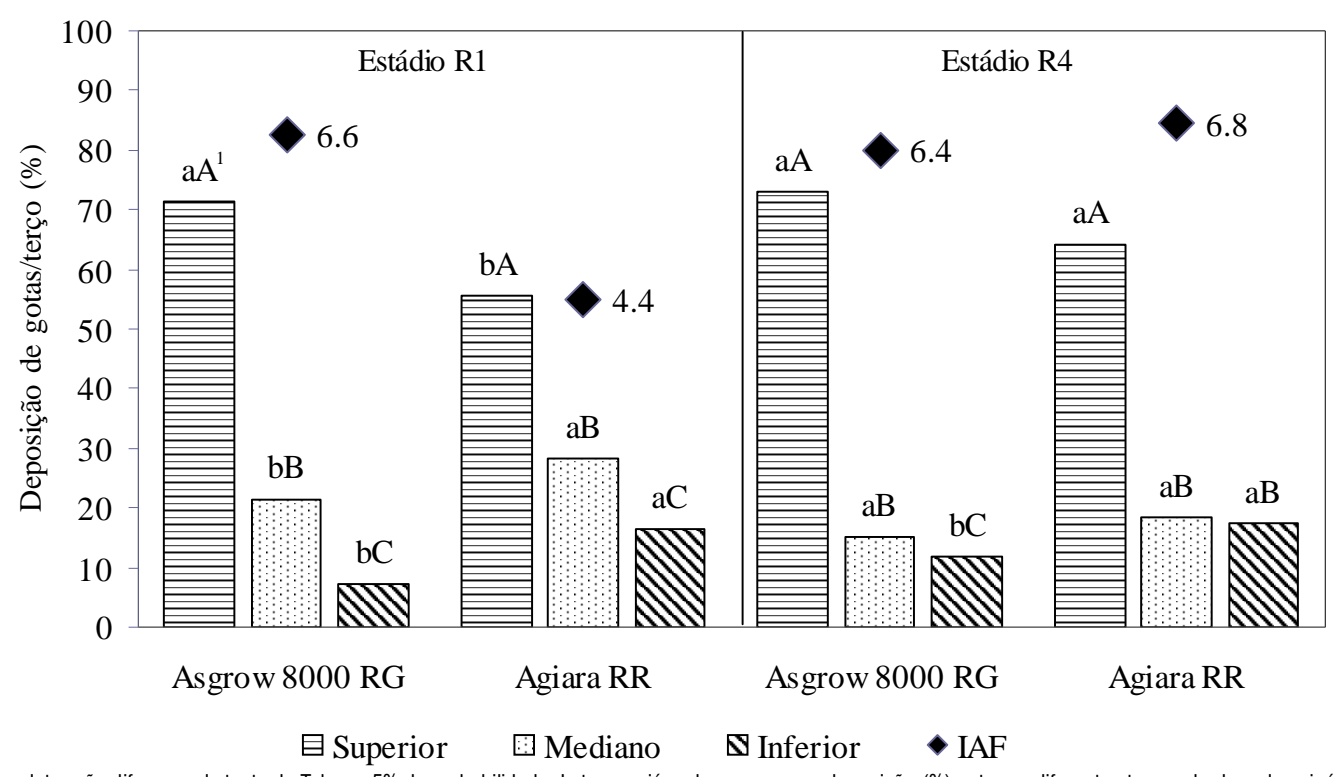

1 Colunas com a mesma letra não diferem pelo teste de Tukey a 5\% de probabilidade. Letras maiúsculas comparam deposição (\%) entre os diferentes terços do dossel e minúsculas comparam cultivares Figura 1. Porcentagem de deposição de gotas nos três terços do dossel em duas cultivares de soja, considerando-se o índice de área foliar, em aplicações realizadas nos estádios fenológicos R1 e R4

Relacionando os dados de porcentagem de cobertura com o IAF das cultivares no momento das aplicações observa-se, na cultivar Agiara RR, deposição de gotas mais homogênea no dossel da planta na aplicação em R1, em que a planta apresentava IAF menor $(4,4)$. Este resultado evidencia a importância do IAF sobre a eficácia da aplicação, como já mencionado no trabalho de Ozkan et al. (2006). Estudando a deposição de glifosato em soja, Gazziero et al. (2006) também observaram menor deposição do produto em plantas mais desenvolvidas e, portanto, com mais folhas.

Apesar disto e observando a deposição de gotas nos estádios R1 e R4 na cultivar Asgrow 8000 RG, nota-se uma modificação na deposição de gotas nos terços mediano e inferior do dossel, sem que haja alterações no IAF, indicando que apenas a alteração do IAF não explica as variações observadas na deposição de gotas entre os diferentes terços. É provável que a maior porcentagem de deposição de gotas nos terços inferior e mediano observada na aplicação em R1, quando comparada com a aplicação em R4, esteja relacionada também às diferenças de arquitetura e ao fechamento do dossel, no momento das aplicações. Além das modificações pelo desenvolvimento da planta a estrutura do dossel pode ser modificada também pelas condições meteorológicas, arranjo de plantas e pelo melhoramento, com a alteração da morfologia das plantas (Wells, 1993). Jagers op Akkerhuis et al. (1998) já haviam observado esta relação entre arquitetura de planta e interceptação de calda de pulverização, estudando a cultura da cevada. Esses autores ainda observaram aumento na interceptação de calda com o envelhecimento da folha bandeira, atribuindo esses resultados à maior angulação da folha bandeira sempre que a mesma envelhece, tendendo a se aproximar da horizontal e, desta forma, favorecendo a interceptação das gotas. Referidos autores concluíram que ramos, folhas e espigas afetam, de forma significativa, a deposição de calda na cultura da cevada.
No estádio R1 a cultivar Asgrow 8000 RG já estava com o dossel completamente fechado e, como consequência, apresentava maior barreira física à penetração das gotas até as camadas inferiores do dossel vegetal do que a Agiara RR. A partir do completo fechamento do dossel ocorre, naturalmente, senescência de parte das folhas baixeiras das plantas e a tendência é de que as folhas se concentrem no topo do dossel devido à maior luminosidade e melhores condições para a realização da fotossíntese. Assim, mesmo não havendo alteração no IAF da planta, é possível que a penetração das gotas para o interior do dossel seja dificultada fato que, possivelmente, ocorreu com a cultivar Asgrow 8000 RG; já para a cultivar Agiara RR, que apresentou total fechamento entre linhas, somente na segunda aplicação, tanto o fechamento do dossel quanto o IAF parecem ter contribuído para que houvesse modificação na deposição de gotas.

Esses resultados sinalizam que a cobertura das folhas baixeiras da planta com fungicida é extremamente dependente do IAF e da arquitetura da cultivar no momento da aplicação de vez que as folhas da parte superior do dossel interceptam boa parte das gotas pulverizadas e impedem que as folhas baixeiras recebam a mesma quantidade de ingrediente ativo. Cada cultivar possui características peculiares no que diz respeito à sua arquitetura e variam conforme a época de semeadura, condições ambientais e estádio de desenvolvimento da cultura. Além do efeito que exercem sobre a qualidade da aplicação, tais características criam condições de microclima dentro do dossel que podem favorecer a ocorrência ou rápido estabelecimento da doença (Wilson et al., 1998).

Mesmo havendo amplitude considerável entre as pontas no que se refere à deposição de gotas, esta diferença não se expressou de forma tão evidente nos resultados de AACPF em virtude, provavelmente, do número de gotas depositado pelas pontas de pulverização utilizadas se manter acima de 30 gotas $\mathrm{cm}^{-2}$ na maioria dos casos, exceto para o terço inferior, que exerceu influência menor na $\mathrm{AACPF}$ em razão do menor peso 
que recebeu para o cálculo (30\%). Ditos valores de número de gotas encontrados estão muito próximos dos valores considerados adequados para fungicidas sistêmicos, de acordo com Christofoletti (1999) e Ugalde (2005), que são de 30 a 40 gotas $\mathrm{cm}^{-2} \mathrm{e} 45$ gotas $\mathrm{cm}^{-2}$, respectivamente.

Por outro lado, caso se observem as diferenças de densidade de gotas e porcentagem de deposição por terço, é possível perceber também, claramente, que na cultivar Agiara $\mathrm{RR}$, que recebeu maior número de gotas nos três terços, o controle da doença foi melhor. A eficácia do melhor programa de controle na cultivar Agiara RR foi de 95\%, ao passo que na cultivar Asgrow 8000 RG este valor foi de $84 \%$, considerandose a média das três pontas de pulverização.

$\mathrm{Na}$ Tabela 3 são apresentados os resultados de AACPF conforme a ponta de pulverização e o programa de controle empregado. Na cultivar Agiara RR os menores valores de AACPF foram observados nos tratamentos com a utilização da ponta TJ-60 11002, seguidos pela ponta XR 11002 e, com os maiores valores de AACPF pela ponta, a TT 11002; a mesma tendência foi observada na cultivar Asgrow 8000 RG, embora não de forma significativa.

Em relação aos programas de controle químico empregados, aqueles com aplicação de fungicida foram sempre superiores à testemunha sem aplicação. Embora o desempenho dos fungicidas tenha sido semelhante em ambas as cultivares, na cultivar Asgrow $8000 \mathrm{RG}$ a amplitude entre tratamentos foi mais expressiva. O melhor controle da doença em ambas as cultivares foi alcançado pela aplicação de azoxistrobina + ciproconazol, que apresentou os menores valores de AACPF, não diferindo dos tratamentos com tebuconazol + carbendazim na cultivar Agiara RR. Miles et al. (2003) também observaram superioridade da mistura triazol + estrobilurina no controle da ferrugem asiática.
O rendimento de grãos da cultura da soja foi afetado pelos programas de controle, pontas de pulverização e cultivares utilizadas; entretanto, a magnitude das diferenças ocorreu em escala menor do que para os dados de AACPF (Tabela 4). O incremento médio pela aplicação dos fungicidas foi de $53,17 \%$ na Cultivar Asgrow 8000 RG e 29,89\% na cultivar Agiara RR, resultados que apontam para a resposta diferenciada das cultivares ao controle químico pois, mesmo apresentando maior redução da AACPF pela aplicação dos fungicidas, a cultivar Agiara RR apresentou incrementos inferiores de rendimento.

Na cultivar Asgrow 8000 RG não houve diferença significativa no rendimento de grãos entre os diferentes fungicidas estudados, exceto para o fungicida tebuconazol + carbendazim, que foi superior quando aplicado com a ponta TJ-60 11002. Quando comparados à testemunha, os fungicidas sempre se mostraram superiores.

Na cultivar Agiara RR os tratamentos com fungicida foram superiores à testemunha sem controle e não diferiram entre si, exceto para o tratamento com tebuconazol + carbendazim, que apresentou menor rendimento em relação à azoxistrobina + ciproconazol quando aplicado com a ponta TT 11002. Este tratamento apresentou a maior AACPF entre todos os tratamentos que receberam aplicação de fungicida na cultivar Agiara RR. Relacionando-se esses resultados com a densidade de gotas observa-se claramente menor deposição de gotas neste tratamento nas duas aplicações e, em R4, os terços mediano e inferior receberem menos de 25 gotas $\mathrm{cm}^{-2}$. O maior número de gotas observado no terço inferior quando comparado ao mediano está relacionado, provavelmente, ao diâmetro das gotas depositadas em cada terço visto que, quanto maior o DMV menor a densidade de gotas.

Em relação às pontas de pulverização maiores rendimentos de grãos foram alcançados pela ponta TJ-60 11002 na cultivar

Tabela 3. Área Abaixo da Curva de Progresso da Ferrugem (AACPF) em duas cultivares de soja submetidas à aplicação de três programas de controle químico com três pontas de pulverização

\begin{tabular}{|c|c|c|c|c|c|c|c|c|}
\hline \multirow[b]{2}{*}{ Ponta } & \multicolumn{3}{|c|}{ A 8000 RG } & \multirow[b]{2}{*}{ Média } & \multicolumn{4}{|c|}{ Agiara RR } \\
\hline & testemunha & azoxi. +cipro². & tebu. + carben ${ }^{3}$. & & testemunha & azoxi. +cipro². & tebu. + carben ${ }^{3}$. & Média \\
\hline XR 11002 & $885,37 \mathrm{aA}^{1}$ & $139,80 \mathrm{abc}$ & 188,72 bB & $404,63 \mathrm{~b}$ & $1352,31 \mathrm{aA}$ & $65,62 \mathrm{aB}$ & $67,51 \mathrm{abB}$ & $495,15 \mathrm{a}$ \\
\hline TJ 11002 & 896,62 aA & $102,91 \mathrm{BC}$ & $153,58 \mathrm{bB}$ & $384,37 \mathrm{~b}$ & $1362,31 \mathrm{aA}$ & $51,20 \mathrm{aB}$ & $57,40 \mathrm{bB}$ & $490,31 \mathrm{a}$ \\
\hline TT 11002 & $893,37 \mathrm{aA}$ & $166,92 \mathrm{aC}$ & $258,17 \mathrm{aB}$ & $439,49 a$ & $1328,66 \mathrm{aA}$ & $79,19 \mathrm{aB}$ & $92,63 \mathrm{aB}$ & $500,16 a$ \\
\hline Média & $891,79 \mathrm{~A}$ & $136,54 \mathrm{C}$ & $200,16 \mathrm{~B}$ & 439,49 & $1347,76 \mathrm{~A}$ & $65,34 \mathrm{~B}$ & $72,51 \mathrm{~B}$ & 495,21 \\
\hline C.V. (\%) & \multicolumn{4}{|c|}{5,46} & \multicolumn{4}{|c|}{3,88} \\
\hline
\end{tabular}

1 Valores seguidos da mesma letra maiúscula na linha e minúscula na coluna não diferem pelo teste de Tukey a $5 \%$ de probabilidade

${ }^{2}$ azoxistrobina + ciproconazol $\left(60+24 \mathrm{~g} \mathrm{ha}^{-1}\right.$ de i.a. $)$

${ }^{3}$ tebuconazol + carbendazim $\left(100+250 \mathrm{~g} \mathrm{ha}^{-1}\right.$ de i.a)

Tabela 4. Rendimento de grãos $\left(\mathrm{kg} \mathrm{ha}^{-1}\right)$ em duas cultivares de soja submetidas à aplicação de três programas de controle químico com três pontas de pulverização

\begin{tabular}{|c|c|c|c|c|c|c|c|c|}
\hline \multirow{2}{*}{ Ponta } & \multicolumn{4}{|c|}{ Asgrow 8000 RG } & \multicolumn{4}{|c|}{ Agiara RR } \\
\hline & testemunha & azoxi. +cipro ${ }^{2}$. & tebu. + carben ${ }^{3}$. & Média & Testemunha & azoxi. + cipro $^{2}$ & tebu. + carben ${ }^{3}$. & Média \\
\hline XR 11002 & $1986,52 a^{1}$ & $3283,17 \mathrm{aA}$ & $3089,77 \mathrm{abA}$ & 2786,49 a & $1962,62 \mathrm{aB}$ & $2283,23 \mathrm{bA}$ & $2382,27 \mathrm{abA}$ & $2209,37 \mathrm{~b}$ \\
\hline TJ 11002 & $1982,77 \mathrm{aC}$ & $2902,79 \mathrm{abB}$ & $3348,27 \mathrm{aA}$ & $2744,61 \mathrm{ab}$ & $1865,87 \mathrm{aB}$ & $2677,69 \mathrm{aA}$ & $2616,05 \mathrm{aA}$ & $2386,54 \mathrm{a}$ \\
\hline TT 11002 & $1977,77 \mathrm{aB}$ & $2775,93 \mathrm{bA}$ & 2819,14 bA & 2524,28 b & $1803,37 \mathrm{aC}$ & $2455,10 \mathrm{abA}$ & $2216,62 \mathrm{bB}$ & $2158,36 \mathrm{~b}$ \\
\hline Média & $1982,35 \mathrm{~b}$ & 2987,30 a & $3085,73 \mathrm{a}$ & 2685,13 & $1877,29 \mathrm{~b}$ & $2472,01 \mathrm{a}$ & 2404,98 a & 2158,36 \\
\hline C.V.\% & \multicolumn{4}{|c|}{9,15} & \multicolumn{4}{|c|}{5,88} \\
\hline
\end{tabular}

${ }_{1}^{1}$ Médias seguidas da mesma letra maiúscula na linha e minúscula na coluna não diferem pelo teste de Tukey a $5 \%$ de probabilidade

2 azoxistrobina + ciproconazol $\left(60+24 \mathrm{~g} \mathrm{ha}^{-1}\right.$ de i.a. $)$

3 tebuconazol + carbendazim $\left(100+250 \mathrm{~g} \mathrm{ha}^{-1}\right.$ de i.a) 
Agiara RR, independentemente do fungicida utilizado. Na cultivar Asgrow 8000 RG as pontas TJ-60 11002 eXR 11002 não diferiram significativamente. Apesar de não diferir das demais em alguns casos, a ponta TT 11002 apresentou os menores níveis de rendimento de grãos nas duas cultivares utilizadas.

\section{ConclusõEs}

1. A ponta TJ-60 11002 promoveu cobertura adequada de gotas, nos terços superior e mediano das plantas nas duas cultivares e, no terço inferior, apenas na cultivar Agiara RR.

2. O índice de área foliar das cultivares estudadas afetou a deposição de gotas no seu dossel e deve ser considerado na escolha da ponta de pulverização adequada.

\section{LITERATURA CITADA}

Campbell, C. L.; Madden, L. V. Monitoring epidemics: Diseases. In: Campbell, C. L.; Madden, L. V. (ed.) Introduction to plant disease epidemiology. New York: J. Wiley, 1990. cap.6, p.107-128.

Chaim, A.; Castro, V. L. S. S.; Corrales, M. C.; Galvão, J. A. H.; Abral, O. M. R.; Nicolella, G. Método para monitorar perdas de agrotóxicos na cultura do tomate. Pesquisa Agropecuária Brasileira, v.34, p.741-747, 1999.

Christofoletti, J. C. Pulverização ou aplicação? São Paulo: Teejet South America. 1999. 71 p. Boletim Técnico BT-01/99

Cross, J. V.; Walklate, P. J.; Murray, R. A.; Richardson, G. M. Spray deposits and losses in different sized apple trees from an axial fan orchard sprayer: 2. Effects of spray quality. Crop Protection, v.20, p.333-343, 2001.

Cunha, J. P. A. R. da; Moura, E. A. C.; Silva Júnior, J. L. da; Zago, F. A.; Juliatti, F. C. Efeito de pontas de pulverização no controle químico da ferrugem da soja. Engenharia Agrícola, v.28, p.283-291, 2008.

Cunha, J. P. A. R. da; Reis, E. F.; Santos, R. O. Controle químico da ferrugem da soja em função da ponta de pulverização e volume de calda. Ciência Rural, v.36, p.1360-1366, 2006.

Cunha, J. P. A. R.; Teixeira, M. M.; Coury, J. R.; Ferreira, L. R. Avaliação de estratégias para redução da deriva de agrotóxicos em pulverizações hidráulicas. Planta Daninha, v.21, p.325-32, 2003.

Farinha, J. V.; Martins, D.; Costa N. V.; Domingos, V. D. Deposição da calda de pulverização em cultivares de soja no estádio R1. Ciência Rural, v.39, p.1738-1744, 2009.

Fehr, W. R.; Caviness, C. E. Stages of soybean development. Ames: Iowa State University, 1981. 12p. Special Report, 80

Gazziero, D. L. P., C. D. G. Maciel, R. T. Souza, E. D. Velini, C.E. Prete, e W. Oliveira Neto. Deposição de glyphosate aplicado para controle de plantas daninhas em soja transgênica. Planta Daninha, v.24, p.173-181, 2006.

Godoy, C. V.; Koga, L. J.; Canteri, M. G. Diagrammatic scale for assessment of soybean rust severity. Fitopatologia Brasileira, v.31, p.63-68, 2006.

Hartman, G. L.; Miles, M. R.; Frederick, R. D. Breeding for resistance to soybean rust. Plant Disease, v.89, p.664-666, 2005.
Jagers op Akkerhuis, G. A. J. M.; Axelsen, J. A; Kjær, C. Towards predicting pesticide deposition from plant phenology: A study in spring barley. Pesticide Science, v.53, p.252-262, 1998.

Juliatti, F. C.; Polizel, A. C.; Balardin, R. S.; Vale F. X. R. Ferrugem da soja - epidemiologia e manejo para uma doença reemergente. Revisão Anual de Patologia de Plantas, v. 13, p.351-395, 2005.

Medice, R.; Alves, E.; Assis, R. T de; Magno Júnior, R. G.; Lopes, E. A. G. L. Óleos essenciais no controle da ferrugem asiática da soja Phakopsora pachyrhizi Syd. \& P. Syd. Ciência e Agrotecnologia, v.31, p.83-90, 2007.

Miles, M. R.; Hartman, G. L.; Levy, C.; Morel, W. Current status of soybean rust control by fungicides. Pesticide Outlook, v.14, p.197-200, 2003.

Ozeki, Y.; Kunz, R. P. Tecnologia de aplicação aérea - Aspectos práticos. In: Guedes, J. V. C.; Dornelles S. H. B. (ed.) Tecnologia e segurança na aplicação de agrotóxicos: Novas tecnologias. Santa Maria: UFSM, 1998. p.65-78.

Ozkan, H. E.; Zhu, H.; Derksen, R. C.; Guler, H.; Krause, C. R. Evaluation of various spraying equipment for effective application of fungicides to control asian soybean rust. Aspects of Applied Biology 77. International Advances in Pesticide Applications 2006, Cambridge: Robinson College, 2006. p.423-431.

Peixoto, C. P. Análise de crescimento e rendimento de três cultivares de soja (Glicyne max (L) Merrill) em três épocas de semeadura e três densidades de plantas. Piracicaba: ESALQ/USP, 1998. 151p. Tese Doutorado

Raetano, C. G. Assistência de ar e outros métodos de aplicação a baixo volume em culturas de baixo fuste: A soja como modelo. Summa Phytopathologica, v.33, p.105-6, 2007.

Santos, J. A.; Juliatti, F. C.; Santos, V. A.; Polizel, A. C.; Juliatti, F. C.; Hamawaki, O. T. Caracteres epidemiológicos e uso da análise de agrupamento para resistência parcial à ferrugem da soja. Pesquisa Agropecuária Brasileira, v.42, p.443-447, 2007.

Soares, R. M.; Rubin, S. de A. L; Wielewicki, A. P; Ozelame, J. G.; Fungicidas no controle da ferrugem asiática (Phakopsora pachyrhizi) e produtividade da soja. Ciência Rural, v.34, p.1245-1247, 2004.

Ugalde, M. G. Controle de ferrugem asiática (Phakopsora pachyrhizi Sidow) na cultura da soja. Santa Maria: UFSM, 2005. 66p. Dissertação Mestrado

Viana, R. G. Ferreira, L. R.; Teixeira, M. M.; Cecon, P. R.; Souza, G. V. R. de. Deposição de gotas no dossel da soja por diferentes pontas de pulverização hidráulica e pressões de trabalho. Engenharia na Agricultura, v.16, p.428-435, 2008.

Walklate, P. J. A simulation study of pesticide drift from an airassisted orchard sprayer. Journal of Agricultural Engineering Research, v.51, p.275-284, 1992.

Wells, R. Dynamics of soybean growth in variable planting patterns. Agronomy Journal, v.85, p.44-48, 1993.

Wilson, P. A.; Chakrabrty, S. The virtual plant: A new tool for the study and management of plant diseases. Crop Protection, v.17, p.231-239, 1998. 